\title{
Soinua, zarata, musika: argi al daude mugak?
}

Sound, noise, music: are the boundaries clear?

Marta Urdanpilleta Landaribar*

Gipuzkoako Ingeniaritza Eskola (UPV/EHU)

LABURPENA: Zure bizilagun gaztearen motorrak ez al zaitu lasai jaten uzten? Etxe azpiko tabernarekin ezin al duzu lo egin? Ez al duzu zure bikotekidearen solasa jatetxe batean ulertzen, ondoan badago ere? Zaratarengatik dela ados egongo ginateke guztiok. Halere, zarataren mugak ez dira horren argiak: zuri musika iruditzen zaizuna, zure amonarentzat zarata hutsa izan daiteke. - «Itzal ezak/ezan irrati hori, arraio! Buruko mina besterik ez zidak/zidan ematen zarata horrek!»- entzungo zenuen noizbait, beharbada, gaztetan. Ikusiko dugun bezala, batzuetan ez da erraza soinua, zarata eta musikaren arteko mugak ondo zehaztea.

HITZ GAKOAK: akustika, soinua, zarata, musika.

ABSTRACT: Does your neighbour's motorbike disturb you at meal? Are you not able to sleep properly because of the tavern below your flat? When you have lunch at a restaurant, are you not able to listen to your partner, although he/she seats beside you? We would all admit that this is because of noise. Nevertheless, limits of noise are not that clear: what is music for you may be just noise for your grandma: "For God's sake, turn off this radio, please! It only causes me a headache!»- you might have heard at your eighteens. As we will see, sometimes it is not easy to delimit the boundaries among sound, noise and music.

KEYWORDS: acoustics, sound, noise, music.

\footnotetext{
* Harremanetan jartzeko / Corresponding author: Marta Urdanpilleta Landaribar. Fisika Aplikatua I saila, Gipuzkoako Ingeniaritza Eskola (GIE/EIG), Euskal Herriko Unibertsitatea (UPV/EHU), Europa plaza, 1. 20018 Donostia, Euskal Herria. - marta. urdanpilleta@ehu.eus-https://orcid.org/0000-0002-4078-8184.

Nola aipatu / How to cite: Urdanpilleta Landaribar, Marta (2019). «Soinua, zarata, musika: argi al daude mugak?»; Ekaia, 35, 2019, 277-290. (https://doi.org/10.1387/ekaia.20041).

Jasoa: 9 uztaila, 2018; Onartua: 3 azaroa, 2018.

ISSN 0214-9001 - eISSN 2444-3255 / (c) 2019 UPV/EHU
}

cc)(i) () Obra hau Creative Commons Atribución 4.0 Internacional-en lizentziapean dago 


\section{SARRERA}

1 Formulako 2014ko denboraldian, lehenengo aldiz V6 turbo motor hibridoak ezarri ziren, eta beraz, arautegi honi jarraituz, talde guztiek garatu behar izan zituzten horrelako motorrak zeramatzaten auto berriak. Nobedade hauek zirela eta, denboraldiko lehenengo lasterketetan, eztabaida aparta piztu zen: zale asko kexu zeuden, autoen soinua «oso baxua» zela esanez. Pilotu askok ere iritzi hau partekatzen zuten: «Boxetako horma taberna bat baino isilago dago» adierazi zuen Sebastian Vettelek, ordurako 1 Formulako lau aldiz munduko txapeldunak [1]; «1 Formula ikusgarria izan behar duela uste dut, eta soinua alderdi garrantzitsuenetarikoa da» zioen pilotu alemaniarrak. Horrela, 1 Formulako lasterketetan, soinu-bolumen altua esperientziaren eta ikuskizunaren parte da, noski: inork ez luke nahi autoek garbigailu zahar baten soinua edukitzea, ezta ere inongo soinurik ez igortzea. Bernie Ecclestone, 1 Formulako buru exekutiboa ere, izututa zegoen turbo motor berrien hots pobrearekin [2].

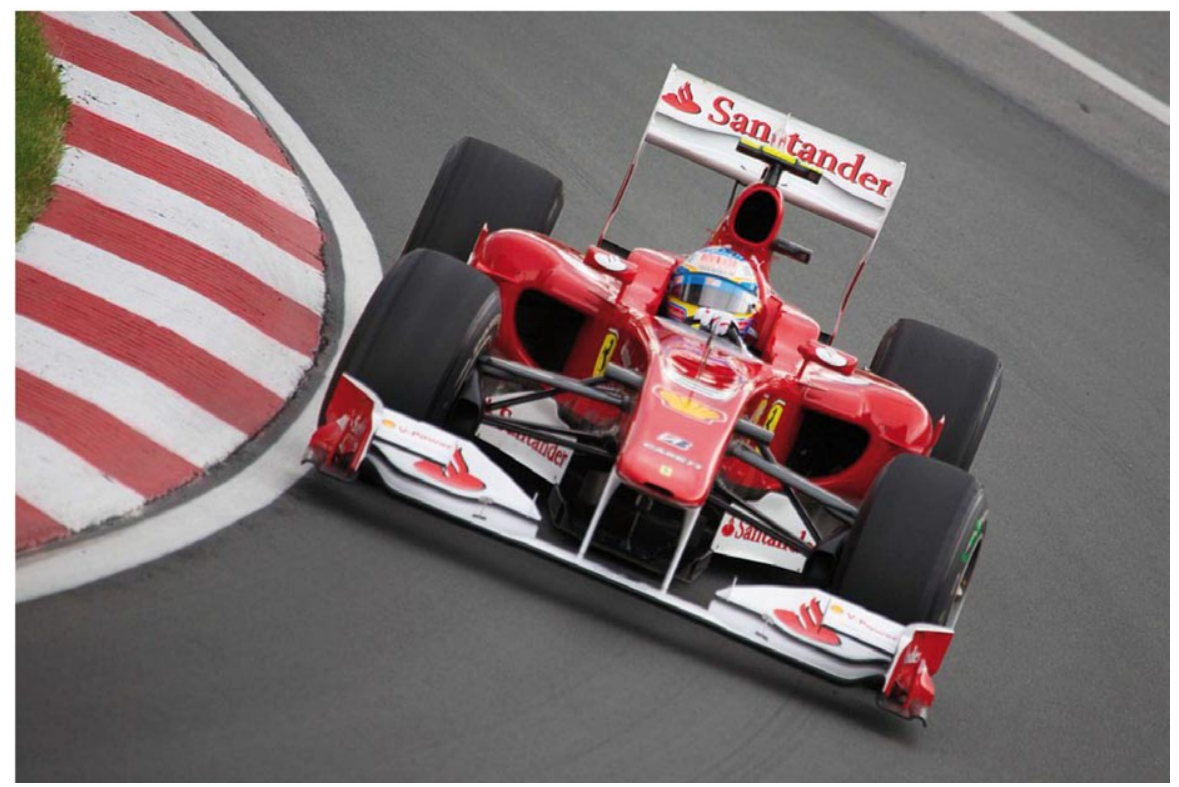

1. irudia. 1 Formulan, $145 \mathrm{~dB}$-ko soinu-mailak lortzen dira. Arg: Mark McArdle, Wikimedia Commons

Berez, kirol hau gobernatzen duen FIA erakundearen neurketen arabera [3], 145 dezibel (dB) inguru igortzen ziren aurreko V8 motor zaharrekin, eta $11 \mathrm{~dB}$ gutxiago (134 dB hain zuzen ere) V6 turbo berriekin. Biak gure belarriaren min-ataritik nabarmen gora! $11 \mathrm{~dB}$-ko jaitsiera txikia iru- 
ditu daiteke halere, eta arraroa egin zaletuek horrelako alde xumeagatik haserre egotea: hau ulertzeko, ordea, kontuan eduki behar dugu dezibelen izaera bitxia.

\section{DEZIBELEN BITXIKERIAK}

Dezibel unitatea aipatu dugu, eta komeni da puntu hau argitzea. Soinua ingurune batean zehar presio-uhin bat hedatzerakoan sortzen da. Ingurunea airea izan daiteke, baino baita ere solido bat edo jariakin bat. Presio seinale hauek Nazioarteko Unitate Sisteman pascaletan $(\mathrm{Pa})$ neurtzen dira. Nahiko ezagunak ditugun sonometroek, soinuen bolumenak zehazteko gailuek, ez dizkigute pantailan soinu-presioak $(p)$ ematen, baizik eta hauetan oinarritutako soinuaren presio-mailak $\left(L_{p}\right)$ : azken hauek dezibeletan $(\mathrm{dB})$ ematen dira, Alexander Graham Bell zientzialariaren omenez. Berez, 10 dezibel 1 bel dira. Soinu presioetatik dezibeletan neurtzen diren soinu-presio mailak kalkulatzeko logaritmoa aplikatu behar dugu, formula honetan adierazten den bezala:

$$
L_{p}=10 \cdot \log _{10}\left(\frac{p}{p_{0}}\right)^{2}
$$

non $p_{0}=2 \cdot 10^{-5} \mathrm{~Pa}$ (20 micropascal) erreferentzia-maila bat den.

Magnitude honengatik eta bere unitatearen definizioagatik, dezibelak maneiatzerakoan kontuz ibili behar gara, ez baitiote ohiko aritmetikari jarraitzen. Pascaletan dauden presio arruntak ohiko moduan konbinatzen dira, hau da, $20 \mathrm{~Pa}+20 \mathrm{~Pa}=40 \mathrm{~Pa}$; dezibelak, ordea, logaritmoak batzen diren moduan konbinatu behar ditugu. Adibidez: bi bozgorailu baditugu, bakoitzak puntu berberean $60 \mathrm{~dB}$-eko soinu-presio maila sortzen bakarrik badaude, pentsa dezakegu beharbada biren konbinazioak puntu horretan $60 \mathrm{~dB}+60 \mathrm{~dB}=120 \mathrm{~dB}$ sortuko dituela. Ez da horrela: $60 \mathrm{~dB}+60 \mathrm{~dB}$ ez dira $120 \mathrm{~dB}$, bazik eta $\sim 63 \mathrm{~dB}$; era berean, $100 \mathrm{~dB}+40 \mathrm{~dB}$ ez dira $140 \mathrm{~dB}$, baizik eta $\sim 100 \mathrm{~dB}(100,0000043 \mathrm{~dB}$, zehatzago esanda).

Beste datua: presio-maila $3 \mathrm{~dB}$-tan handitzen den bakoitzean, seinaleari dagokion energia bikoiztu egiten da; eta presio-maila bati $30 \mathrm{~dB}$ gehitzeko, energia 1.000 aldiz altuagoa behar dugu gutxi gorabehera. Beste modu errazagoan esanda, «asko» kostatzen da presio-maila bat igotzea, seinalearen dezibelak igotzea, portaera ez baita lineala.

Ezaugarri hauek dezibelen izaera logaritmikoa ezagututa ulertzen dira. Eta zergatik logaritmoak? Logaritmoak erabili ordez soinu-presioak neurtzen dituzten pascalak erabiliko bagenitu, gure bizitza arruntean entzuten ditugun soinuen balio tipikoak 1Pa-tik 0,000000000001 Pa-era mugituko lirateke. 
Zero gehiegi, argi dago! Eskala zabal hori nolabait murrizteko edo trinkotzeko, logaritmoak erabili eta aurreko tarte bera $0 \mathrm{~dB}$-tik $120 \mathrm{~dB}$-ra pasatzen zaigu. Zenbaki hauek askoz erosoagoak dira lan egiteko. Gainera, eskala logaritmikoa hobeto adosten da gure entzumeneko sentikortasun-mailara, soinuestimuluekiko daukagun erantzuna ez baita lineala, logaritmikoa baizik.

Nondik nora doa soinu tipikoen dezibelioen tartea? Berez, $0 \mathrm{~dB}$ gure entzumen-ataria da. Hortik behera ezin ditugu soinuak entzun. Eskalaren beste muturrean, hegazkin baten soinu potentzia-maila airea hartzerakoan 120$130 \mathrm{~dB}$ inguruan egon daiteke, eta hortik gora gure entzumenak minak eta kalteak jasaten ditu. Esaten dugu, beraz, gure min-ataria $120 \mathrm{~dB}$ inguruan dagoela. Eztanda nuklear batek 200 bat dB sortuko lituzke, gutxi gorabehera. Kontuan hartu beharrekoa da, baita ere, soinu-iturriarekiko distantziarekin soinuaren barreiatzea dela eta, oztoporik ezean eta iturri puntual eta isotropoa kontsideratuz, ingurune homogeneoan eta airearen absortzioa arbuiatuta, $\sim 6 \mathrm{~dB}$-ko jaitsiera dagoela soinu-mailan distantzia bikoizten den bakoitzean. Hori horrela delako, eztanda nuklear baten $10 \mathrm{~m}$-ra $200 \mathrm{~dB}-\mathrm{ko}$ presio-maila entzuten badugu, $20 \mathrm{~m}$-ra presio-maila $200 \mathrm{~dB}-6 \mathrm{~dB}=194 \mathrm{~dB}$ izango da bakarrik distantzia bikoizteagatik. Horretaz gain, airearen absortzioa eta lurraren gainazalaren eragina dela eta, benetako presio-maila $194 \mathrm{~dB}$ baino txikiagoa litzateke. Hala ere, hobe da hor ez egotea sonometroarekin!

\section{DEZIBEL GEHIEGI EDO GUTXIEGI? ZARATAREN KONTZEPTUA}

1 Formulako adibidearekin jarraikiz, garrantzitsua: bai soinu-maila zaharrak (V8 motorekin) eta bai berriak (motor hibridoak erabiliz) entzumenaren min-ataritik gora daude. Orduan, zaletuek min eta entzumena kaltetzen duten soinu-mailak exijitzen dituzte 1 Formulan! Eta jada min-ataritik gora dagoena eskasa iruditzen zaie, eta pozik joaten dira zirkuituetara belarri-babeskiekin. Zarata edo soinua al da hau?

Puntu honetara iritsita, zarataren definizioa eman beharko genuke:

- [Euskaltzaindiaren hiztegia [4]] Zarata: Hotsa, bereziki aski ozen eta nahasia.

- [Cambridge Dictionary [5]] Noise: A sound or sounds, especially when it is unwanted, unpleasant, or loud.

- [Diccionario María Moliner [6]] Ruido: Sonido no armonioso/ Mezcla inarmónica de sonidos de cualquier naturaleza, como de carruajes u otras cosas moviéndose, de voces o de golpes.

Beste definizio ohiko batean, zarata gizakion jarduerak oztopatzen dituen soinu ez desiratua da. Definizio hau, halere, behatz artetik eror dai- 
teke, hondarra balitz bezala. Soinu-maila magnitude fisiko petoa da, eta beraz era guztiz objektiboan neurtu eta zehaztu daiteke tresneria egokia erabilita, sonometro bat hain zuzen ere. Zarataren kontzeptuak, ordea, kutsu peioratiboa dauka, horregatik subjektiboa da eta ezin dugu tresna batekin zehaztu estimulu bat zarata den ala ez. Hori bai, dagokion soinu-maila inongo anbiguotasunik gabe finka daiteke.

Dezibelioei buruzko beste bitxikeria bat: dezibelio negatiboak existitu existitzen direla. Hain zuzen ere, munduko lekurik isilenetarikoen artean, anekoiko motako sala batek $-20,53 \mathrm{dBA}$-ko marka dauka [7]. Errekor hori presio atmosferikoan gertatu da baina, hutsean soinua transmititzen ez denez, espazioan $-\infty \mathrm{dB}$ edukiko genituzke, definizioari so eginda (hau hurbilketa bat da, galaxiarteko ingurunean ez baitago huts perfekturik). Marka lortzeko, sala anekoiko konkretu hau bereziki ondo isolatu da akustikoki, eta bere barruan soinu posibleen islapenak oso zorrotz saihestu, material oso xurgatzailez estalita hormak, sabaia eta zorua. Bi prozedura hauekin soinua esparruaren barrura sartzea galarazi nahi da, eta sartzekotan, bera desagerraraztea da helburua. Dezibelio negatiboak existitu badaitezke, beren eskalaren zeroa ez da absolutua. Izan ere, hitzarmen batetik dator gure entzumen-atariak finkatzen baitu zeroa. Entzumen oneko pertsona gazte baten entzumen-ataria $0 \mathrm{~dB}$-tan egon dadin, 20 micropascaletan finkatzen da, ad-hoc, presio-mailen definizioaren erreferentzia.

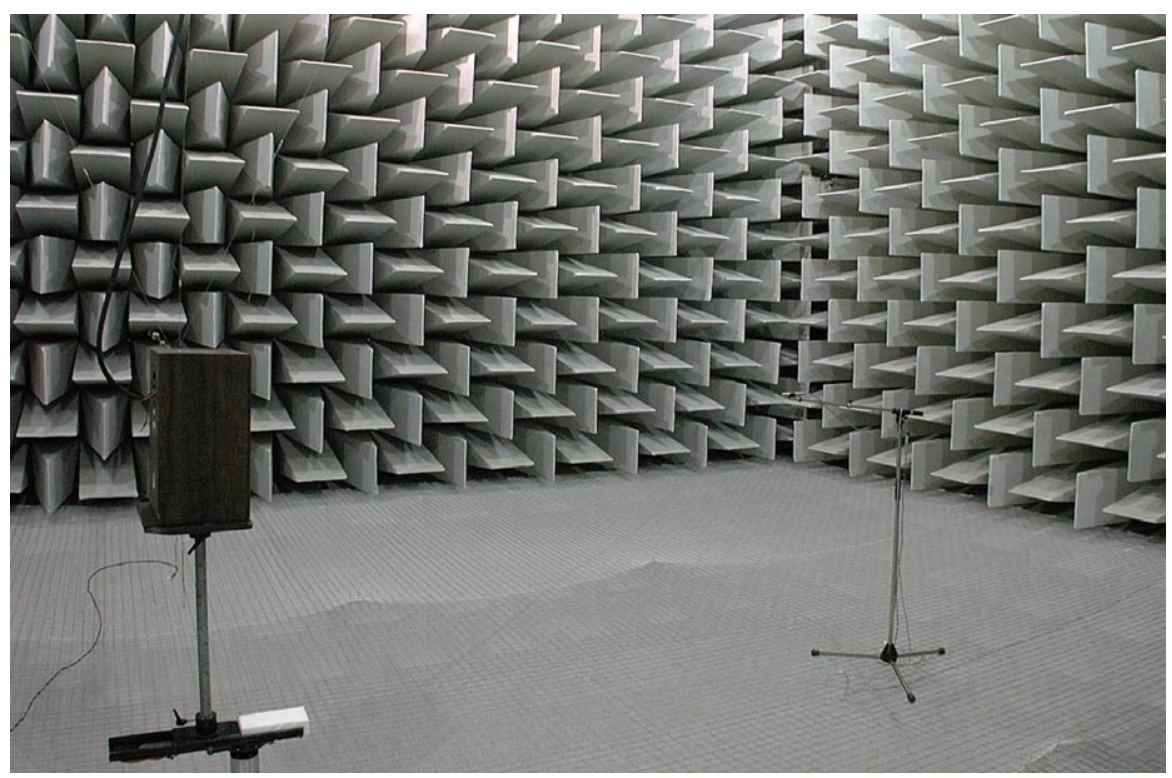

2. irudia. Sala anekoikotan, kanpoarekiko isolamendua eta barruko islapenak zorrotz kontrolatzen dira. Gainazalen itxura konplexua soinua xurgatzeko dagoen azalera efektibo ahalik eta handiena lortzeko da. Arg: JPRoche, Wikimedia Commons. 
Halere, faktore garrantzitsu bat ez dugu oraindik aipatu: soinuaren maiztasuna edo tonua. $60 \mathrm{~dB}$-ko maila daukan soinu bat ez dugu berdin sumatzen soinu hori tonu batean igorrita badago edo bestean. Adibidez, $1.000 \mathrm{~Hz}$-ko maiztasuna daukan $10 \mathrm{~dB}$-ko soinu bat entzungo luke entzumen osasuntsuko gazte batek; $50 \mathrm{~Hz}-\mathrm{koa}$, ordea, ez. Entzumenaren sentikortasuna (eta beraz, entzumen-ataria edo min-ataria) desberdina da maiztasunaren arabera. Efektu hau nolabait kuantifikatzeko, sonoritate berdineko kurba isofonikoak definitzen dira, fon unitatearekin batera. 0 foneko kurba isofonikoak maiztasunaren arabera dagoen entzumen-ataria zehaztuko luke. Era berean, 40 foneko kurbaren gainean dagoen edozein bi puntu hartuta, adibidez $1.000 \mathrm{~Hz}$-tan entzundako $40 \mathrm{~dB}$-ko seinaleak eta $200 \mathrm{~Hz}$-tan sumatutako 50 dB-koak, sonoritate edo soinu-bolumen subjektibo komuna edo alderagarria izango lukete.

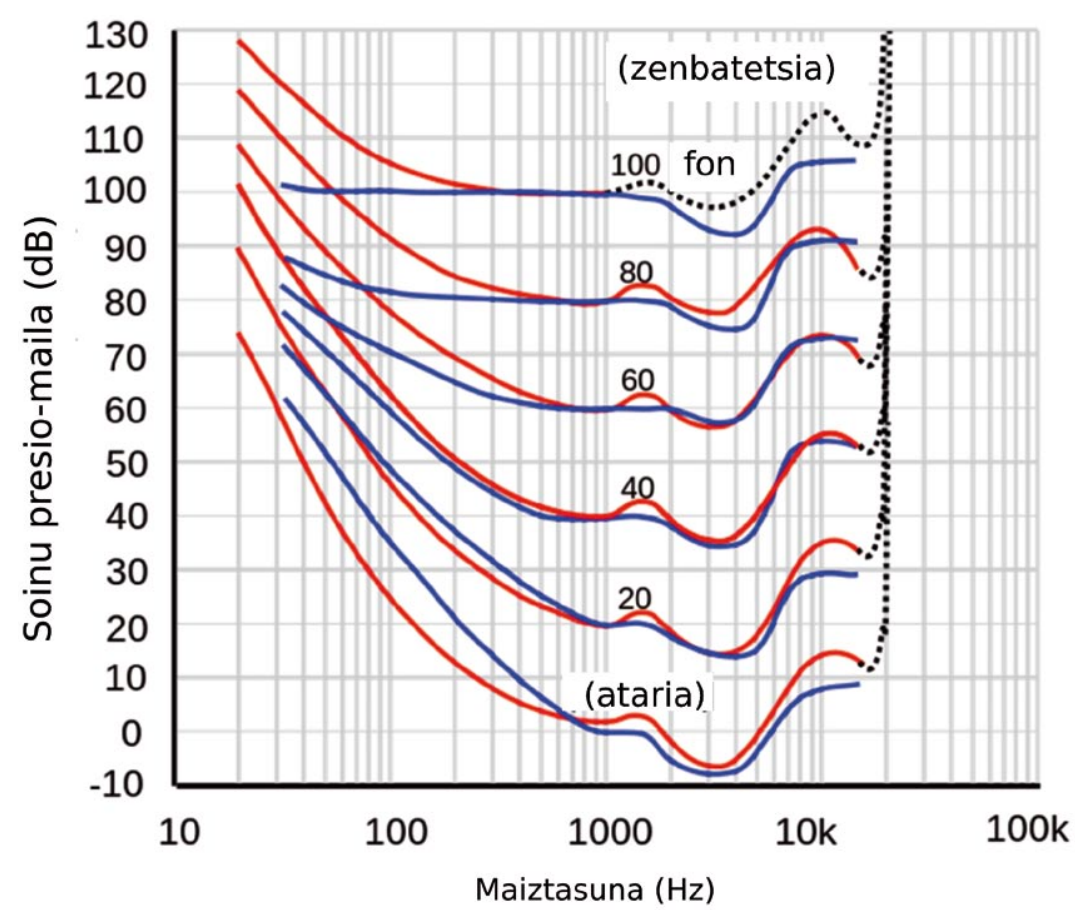

3. irudia. Kurba isofonikoak. Urdinez, Fletcher-Munson-ek emandako jatorrizkoak. Gorriz, 2003ko ISO 226:2003 arauko berrikuspen bat, egun indarrean dagoena. Arg: Lindosland, Wikimedia Commons, egokitua.

Aurreko adibideko sala anekoikoaren $-20,53 \mathrm{~dB}$-ko isiltasun galant hau ikusita, irakurleak uste badu bertan bake-bakean egongo litzatekeela, umeen kasketarik gabe, amaginarrebaren errietarik gabe, ez du asmatzen 
ordea: bertan pertsona gehienek ez dituzte 45 minutu baino gehiago jasaten. Nola da hori? Hauxe da arrazoia: horren isila da gela, non pertsonak bere «barne bizitza» entzuten hasten baitira, nonbait. Ez pentsamenduak, edota burutazio filosofiko posibleak (edo bai?), baizik eta bere bihotzaren taupadak, sabelaren dei isilak, garunaren zirkulazioa. Horren da hunkigarria, sakona eta erradikala sentsazioa, erabat jasanezin bihurtzen dela askorentzako.

Orduan, isiltasuna egungo mundu azeleratuan luxu bat iruditzen bazaigu ere, neurri bateko soinu-maila beharrezkoa daukagu gizakiok; neurrizko dezibelio maila bat behar dugu ondo sentitzeko. Ikusi dugu orduan soinumaila gehiegizkoak kalte egiten duela, baina soinu maila minimo bat behar dugu entzuten hasteko eta baita ere eroso egoteko. Bi muga horien artean, soinuak plazera sortu dezake gugan. Hor, musikarekin topo egiten dugu.

\section{MUSIKAREN KASUA}

Zaratarekin gertatzen den bezala, musikaren mugak difusoak dira, amonaren hasierako adibidean ikusi dugun moduan.

- [Euskaltzaindiaren hiztegia [4]] Musika: Hotsak arau jakinen arabera konbinatzeko artea; antolaketa horren araberako emaitza.

- [Cambridge Dictionary [5]] Music: A pattern of sounds made by musical instruments, voices, or computers, or a combination of these, intended to give pleasure to people listening to it.

- [Diccionario María Moliner [6]] Música: Sucesión de sonidos compuestos, según ciertas reglas, de modo que resulta grata al oído.

4'33' («lau hogeita hamahiru» irakurrita) izeneko bere obra aitzindari eta famatuaren estreinaldian, John Cage Xx. mendeko musikari estatubatuarrak publikoa txundituta utzi zuen: 4 minutu eta 33 segundotan, pieza interpretatu zuen piano-joleak ez zuen inongo soinurik igorri - edo igorri izan nahi, hobeto esanda-. Piezak hiru mugimendu zeuzkan; lehenengo mugimenduaren hasieran, interpreteak pianoko tapa ireki eta eserlekuan geldi geratu zen, teklatua ukitu gabe. Mugimendua bukatzerakoan, tapa itxi zuen. Publikoaren harridurarako, beste bi mugimenduetan berdin egin zuen, beti isilik egonda eta pianoa jo gabe. Horrelako interpretazio batean, piezaren denbora-tarte horretan giro-zaratak hartu zuen normalean musikatzat hartzen dugunaren papera. Edo giro-musikak esan beharko al genuke? Publikoaren arnasak, eserlekuan berriz esartzean entzuleek egiten zituzten soinuak, kanpotik zetozen eta isolatzen ezinezkoak ziren soinuak entzuten ziren, baina gure amonak musikatzat hartuko lukeenik, ezertxo ere ez. Cage-k hausnarketa kontzeptuala eta probokazioa bilatzen bazituen, baita lortu ere zituen, alajaina! 
Halaber, gure bizitza arruntean giro-zaratatzat/soinutzat hartzen ditugunean seinaleen garrantziaz ohartarazi gaituzte aspaldian musikariek. Azken urte hauetan, adibidez, «soinu-paisaia»-ren kontzeptua (ingelesez soundscape) gero eta ezagunagoa da. Autobusa hartzean edota mendira joatean entzuten ditugun soinuak aintzat hartu dira, eta haiek etorkizunerako gordetzeko, grabatu egiten dira. Badirudi gero eta txantxangorri eta txolarre gutxiago daudela gure hiri eta herrietan $[8,9]$, eta beren soinu eta kantuek balio handia daukate, adibidez. Baita ere orain arrunta iruditzen zaigun edozein soinuk. Soinuok eta kantuok grabatuz gero, etorkizunerako gorde daitezke altxor hauek [10]. Halako grabazioak elektronikoki konbinatuz eta manipulatuz, konposatzaile garaikide batzuek (musika konkretua egiten dutenek, hain zuzen ere) musika sortzen dute.

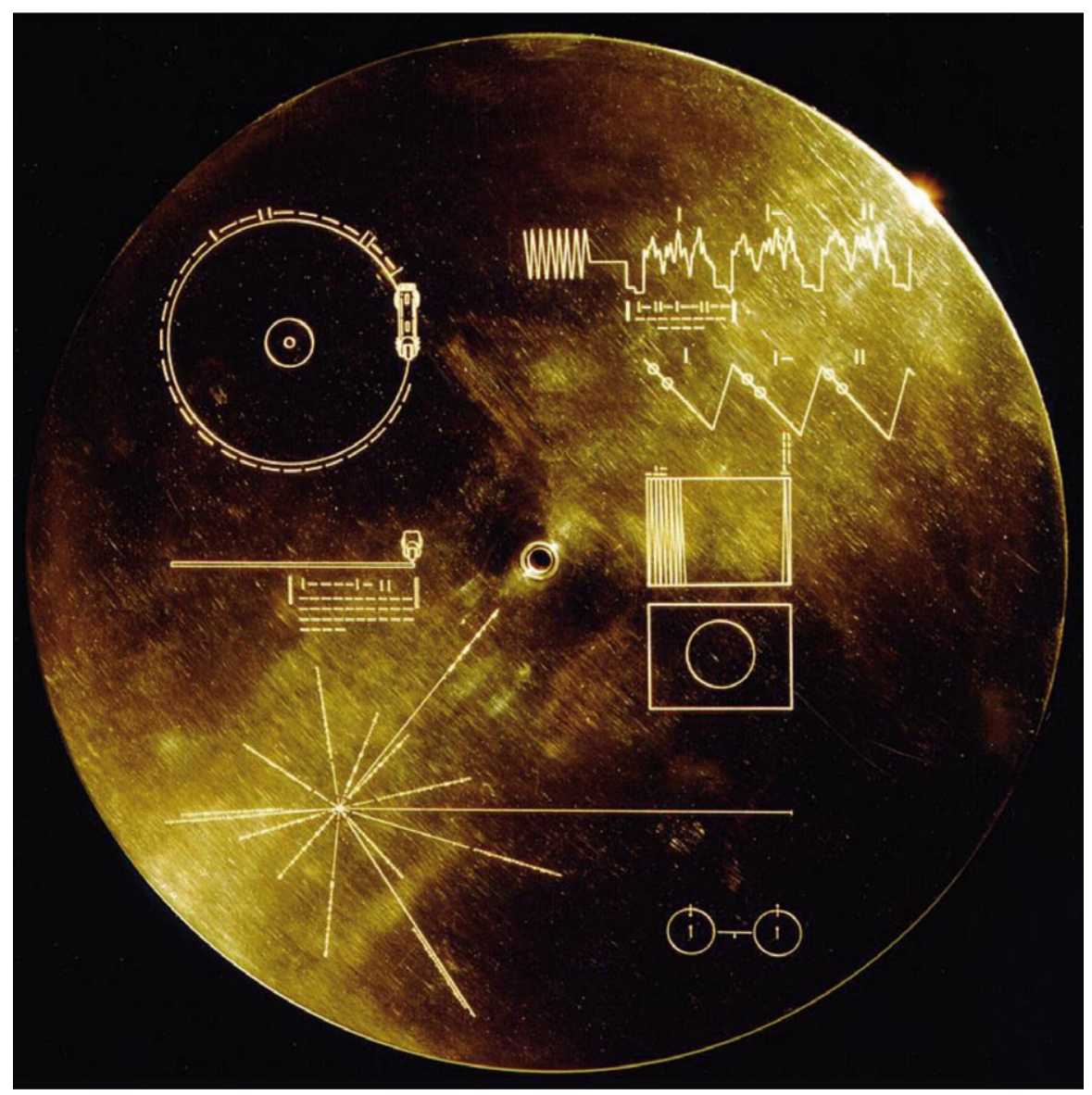

4. irudia. NASA-k Voyager zundan bidalitako Sounds of Earth Golden Record-en estalkia. Arg: NASA/JPL, Wikimedia Commons. 
NASAko Voyager misioetan, Golden Record grabazio famatuan, gizakiok espaziora Lurreko argazki, irudi eta diagramak, musika eta soinuak bidali genituen, noizbait beste organismo inteligenteek informazio hau interpretatu ahal izango dutelakoan. Besteak beste, sumendien, trumoien, igelen, txakurren, suaren, autobusen, musuen, ume txikien soinu eta hotsak. Voyager 1 aizarrarteko espazioan zehar bidaiatzen ari da jada, Eguzki-sistemaz harago; ez dakigu balizko estralurtarrek grabazio hauek soinu, zarata edo musikatzat hartuko ote dituzten. Ezin jakin orduan estralurtarrek, existitzekotan, fenomeno hauekiko sentsibilitatea daukaten ala ez (Steven Spielberg-en 3. Motako Hurbileko Topaketak filmean, estralurtar musikalak ezagutu genituen). Esan dezakegu, hori bai, existitzen direla munduan musika melodiak, tonuak edota erritmoak barneratu, interpretatu eta prozesatzeko gaitasun edo sentsibilitaterik ez duten pertsonak: amusia deitzen zaio nahasmen du honi. Che Guevara, adibidez, erritmoarekiko gorra zen [11]. Jatorri desberdineko amusiak daude, batzuk jaiotzetik, besteak eskuratuak, adibidez istripu edo apoplexia batean gerta daitekeen kalte neurologiko baten ondorioz sortzen direnak. Oliver Sacks neurologoak oso ondo deskribatzen du hau bere Musicofilia liburuan [11]. Gerta daiteke beste pertsonek musikatzat hartzen dutena amusiko batek zarata kontsideratzea. Liburu honetan deskribatutako kasu batean, emakume batek honela erantzuten du galdetzen diotenean zer sentitzen duen musika entzutean: «If you were in my kitchen and threw all the pots and pans on the floor, that's what I hear!». Beste kasu batzuetan, disonantziarekiko amusia egon daiteke ere, eta normalean desatsegina iruditzen zaigun disonantzia «nahiko atsegintzat» hartu [11]. Hemen ere argi geratzen da ez dela erraz musikaren definizio bat ematea.

Musikaren istorian, konposatzaileek askotan musikalak ez diren soinuak eta zaratak txertatu dituzte bere konposizio deskriptibo edo programatikoetan: adibidez, Hector Berlioz-en Symphonie fantastiquen, gillotina batek erortzerakoan egiten duen soinua simulatzen du orkestrak; Pyotr Illiych Tchaikovsky-ren 1802 oberturan, 16 kanoi-hots entzuten dira, eta autoreak interpretazioan benetako kanoiak erabiltzea eskatu zuen. Soinu bortitz hauen baino adibide askoz zirraragarrian, Einojuhani Rautavaara-ren Canctus Articus konposizioan, piezaren oinarri dira Artikoko txorien kantu eta soinuak. Berez, konposatzaileak magnetofoi batekin Finlandiako ipar zirkulu polarraren inguruko txorien kantuen grabazioak egin zituen pieza sortu ahal izateko.

Soinu ausazkoak, ordenarik gabekoak, harmoniarik gabekoak, ez ditugu orokorrean musikatzat hartzen: musika identifikatzeko daukagun irizpide tradizionala ordena bat aurkitzea da: doinuan edo erritmoan adibidez. Halere, musika landu garaikideko kontzertu askotan, instrumentu musikalak ez dira era tradizionalean jotzen: pianoen teklatua ez da behatzekin pultsatzen, baizik eta bere sokei kolpeak ematen zaizkie edota eskuen edo objektuen bidez igurzten dira. Biolinekin orain arte sortu ez ziren soinuak 
sortzen dira. Harraskatu, arraspatu, kolpekatu, kirrinkatu, urratu egiten dira sokak. Globoak berariaz lehertzen dira agertokian musika pieza baten erdian. Non dago hemen soinu, zarata eta musikaren arteko muga?

\section{MUSIKA, ZARATA ETA OSASUNA}

Horren efektu onuragarria eduki dezake soinuak osasunean, non medikuntzan oso erabilia den gaixotasunen eboluzioa hobetzeko [12, 13]; ondorio txarrak ere eduki ditzake, arma akustikoak garatzen ari baitira zenbait herrialdetan [14]. Halaber, definizioari so eginda, musikari baten kontzientziarako musika dena, bere entzumenarentzat zarata izan daiteke. Ezagunak dira Rock izarren entzumen-arazoak [15] (Phil Collins-en kasua, AC/ DC-ko Brian Johnson-ena, Metallica-ko Lars Ulrich bateriarena). Azkenean, soinu-maila altuen aurrean egotea denbora luzean ez da doan ateratzen. Musika klasikoko, rock edo jazzeko musikariek, besteak beste, entzumenezko arazo profesionalak eduki ditzakete orkestran egotean jasan behar dituzten dezibel altuengatik. Adibidez, hiperakusia, hipoakusia, akufenoa edo distortsioa $[15,16]$.

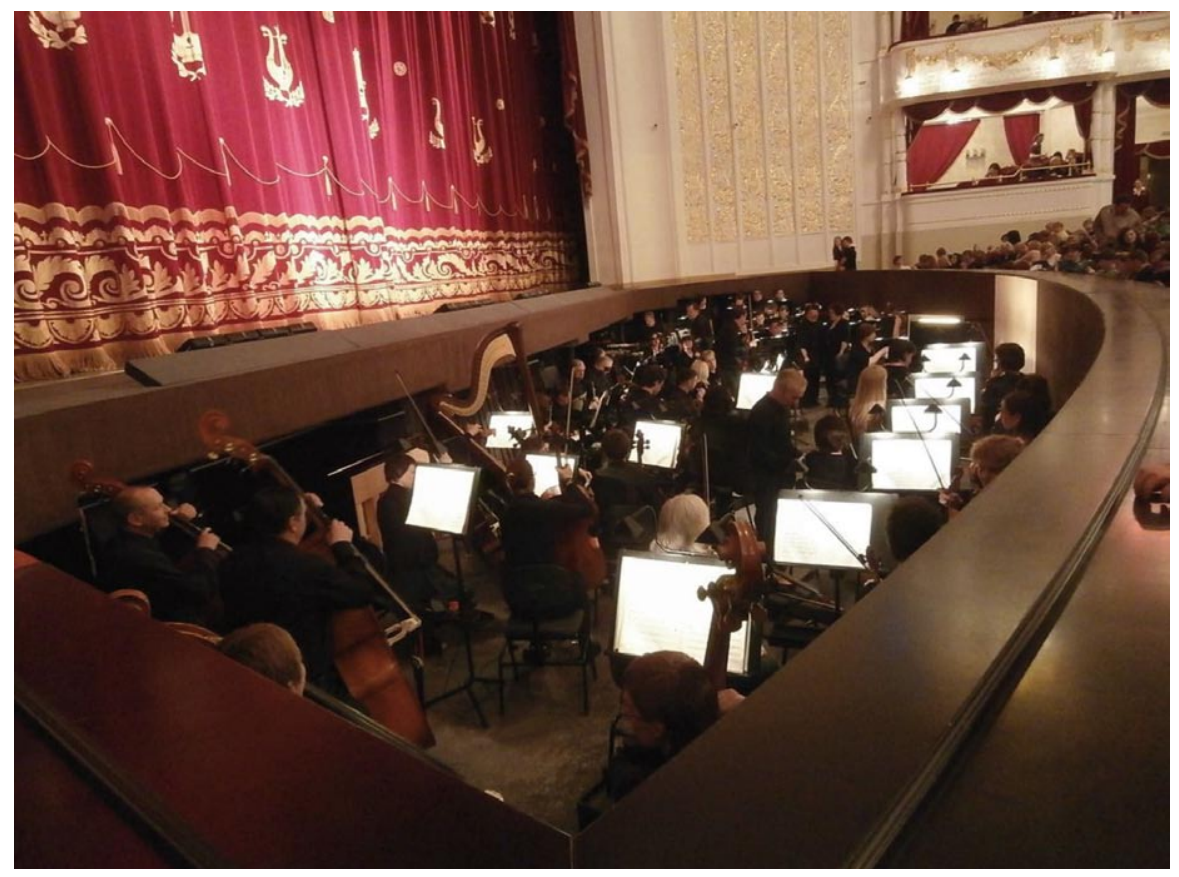

5. irudia. Orkestra baten pezoian, $90 \mathrm{~dB}(\mathrm{~A})$ gorako presio-maila baliokide jarraituak $\left(\mathrm{L}_{\text {eq }}\right)$ jasan daitezke opera baten antzezpenean. Arg: Pjotr Mahhonin, Wikimedia Commons. 
Ikertzaile batzuek Madama Butterfly operaren antzezpenetako 3 orduetan orkestrako zenbait musikarik jasan zituzten maila baliokide jarraituak $\left(\mathrm{L}_{\mathrm{eq}}\right)$ neurtu zituzten, eta maila altuena tronpeta-jotzaileek jasan zutela ohartu ziren: 92,3-95,3 $\mathrm{dB}(\mathrm{A})$, hain zuzen ere (alderatzeko, orkestra-zuzendariak $83,3 \mathrm{~dB}(\mathrm{~A}))$ [17]. Horrek, zer esan nahi du? Hiru ordu horietan zehar tronpeta-jotzaileari iristen zaion soinu maila (edo bestela esanda, energia akustikoa) aldakorra da: tarte isiletan baxua eta beste batzuetan oso altua. Berdinak dira, oro har hiru ordu horietan iristen den energia kopurua eta maila baliokide jarraituaren balioa duen soinu konstante batek sortzen duena.

Gogora dezagun maila baliokide karratuarekin $T$ denbora jakin batean (kasu honetan, operaren iraupena) neurtutako soinuko presio-maila integratzen dela, formula honi jarraituz:

$$
L_{e q}=10 \cdot \log _{10}\left[\frac{1}{T} \int_{t_{1}}^{t_{2}}\left(\frac{p_{A}(t)}{p_{0}}\right)^{2} d t\right]
$$

non $T=t_{2}-t_{1}$ eta $p_{0}=2 \cdot 10^{-5} \mathrm{~Pa}$ diren.

Maila baliokideak erabilgarriak dira, adibidez, segurtasunaren aldeko araudietan. Aipa dezakegu 286/2006 espainiar dekretuak [18] zaratarekin erlazionatutako arriskuen aurreko langileen osasuna eta segurtasuna arautzen dituela, eta horren arabera langile batek 8 orduko lanegun batean jasan dezakeen presio-maila baliokide jarraitu maximoa $87 \mathrm{~dB}(\mathrm{~A})$ dela. Horrek ematen digu, nolabait, eguneko energia akustikoaren dosi maximoa langile batentzat Halaber, $85 \mathrm{~dB}(\mathrm{~A})$ gaindituz gero babes-neurriak hartzea derrigorrezkoa da:, belarri-babeskiak adibidez. Gauza da, musikari batek ez duela nahiko belarribabeskirik jartzea, ez lukeelako musika era aproposean entzungo. Musikaren eta aisialdiaren arloan araudi espezifikoa dago horrexegatik [19]. Baina 8 orduko iraupeneko $87 \mathrm{~dB}(\mathrm{~A})$-ko seinale baten energia, 1/4 orduko $102 \mathrm{~dB}$-ko beste seinale baten energiaren berdina da, $\mathrm{L}_{\mathrm{eq}}$ honen definizioa ikusiz gero. Arauarentzat ere bai. Esaten da orduan dosi berdinak direla. Langile batek bere lanpostuan jasandako eguneroko dosia dosimetro deritzen gailuekin neurtzen dira. Kalkuluak eginez gero, 1. taulan agertzen diren baliokidetasunak eman ditzakegu. Egun bakar bateko dosia tronpeta-jotzailearentzat $87 \mathrm{~dB}(\mathrm{~A})$ baino altuagoa izango litzateke, baina kontuan hartu beharra dago urte guztian zehar ez lukeela, beharbada, egunero maila hori jasan beharko.

Taula ikusita, dezibelen izaera logaritmikoa berriro ere nabarmena da: $\mathrm{L}_{\mathrm{eq}}$ maila 3 dezibeletan handitzerakoan, esposizio-denbora erdira jaisten da. Horrela, 5 minututan $105 \mathrm{~dB}(\mathrm{~A})$ jasatea (gutxi gorabehera tabernetan jotzen duten taldeek eragiten dutena), ordu batean kopak hartzeko taberna batean jasotzen den dosiaren baliokidea da ( $94 \mathrm{~dB}(\mathrm{~A})$ inguru), edota 4 ordutan ganbera-musikako kontzertu batean egoteagatik jasotzen dena $(88 \mathrm{~dB}(\mathrm{~A}))$ [19]. 
1. taula. Zaratarekiko esposizio-denbora maximoa $87 \mathrm{~dB}(\mathrm{~A})$-ko eguneko maila baliokide jarraitua lortzeko [18].

\begin{tabular}{cc}
\hline$L^{\text {Aeq, }} / \mathrm{dB}(\mathrm{A})$ & $\begin{array}{c}\text { Esposizio-denbora } \\
\text { maximoa }\end{array}$ \\
\hline 87 & 8 ordu \\
90 & 4 ordu \\
93 & 2 ordu \\
96 & 1 ordu \\
99 & $1 / 2$ ordu \\
102 & $1 / 4$ ordu \\
105 & $71 / 2$ minutu \\
112 & $1 \frac{1 / 2 \text { minutu }}{12}$ minutu \\
117 & 15 segundo \\
\hline
\end{tabular}

\section{ONDORIOAK}

Zientziak, akustikak hain zuzen ere, oinarri kontzeptualak eskaintzen dizkigu zarata, soinua eta musikaren fenomenoak ulertu ahal izateko: eskura dauzkagu magnitude fisikoak, hauek neurtzeko metodoak, edota magnitudeen arteko erlazio teorikoak. Halere, ezin dugu gailu baten bidez kasu guztietan zehaztu soinu bat zarata den ala ez; ezin dugu ezta ere erraz ulertu zergatik daukagun gizakiok musikarekiko zaletasuna, edota zergatik kontsideratzen dugun soinu bat musika. Charles Darwin-en esanez: «As neither the enjoyment nor the capacity of producing musical notes are faculties of the least use to man in reference to his daily habits of life, they must be ranked amongst the most mysterious with which he is endowed.» [20]. Soinuak, zaratak eta musikak muga difusoak dauzkate, ikusi dugun bezala, eta batzuetan ezin ditugu zientifikoki mugatu. Gaiak eztabaida subjektiborako esparru zabala uzten digu, eta zientziaz harago joan behar dugu, orduan. Eta zientzia ederra dela badiogu, eztabaida hau ere oso polita dela esan daiteke.

\section{BIBLIOGRAFIA}

[1] http://www.marca.com/2014/05/08/motor/formula1/gp-espana/1399550607. html. Azken eguneratzea: 2014/05/08.

[2] https://www.independent.co.uk/sport/motor-racing/f1-bernie-ecclestoneadmits-to-being-horrified-by-quiet-engines-on-new-f1-cars-9198886.html. Azken eguneratzea: 2014/03/18. 
[3] http://www.fia.com/sites/default/files/publication/file/FIA\%20F1\%20 Power\%20Unit\%20leaflet.pdf. Azken eguneratzea: 2014.

[4] EUSKALTZAINDIA 2016 Euskaltzaindiaren Hiztegia.

[5] UNIVERSITY OF CAMBRIDGE 2018. Cambridge Dictionary. Cambridge University Press, Cambridge.

[6] MOLINER M. 2007. Diccionario de uso del español. Editorial Gredos, Madrid.

[7] http://www.guinnessworldrecords.com/news/2015/10/microsoft-lab-setsnew-record-for-the-worlds-quietest-place-399444. Azken eguneratzea: 2015/10/02.

[8] TELLERÍA, J. L. 2015. «The decline of a peripheral population of the European robin Erithacus rubecula». Journal of Avian Biology, 46(2), 159-166.

[9] BALMORI, A., HALLBERG, Ö. 2007. «The urban decline of the house sparrow (Passer domesticus): a possible link with electromagnetic radiation». Electromagnetic biology and medicine, 26(2), 141-151.

[10] Irakurle interesatuak txorien kantuen doako erregistro mardula nahi badu entzun, ikus dezala Macaulay Library deritzon web-orrialde zoragarria: http:// macaulaylibrary.org/about. Azken eguneratzea: 2018.

[11] SACKS O. 2009. Musicofilia. Ed. Anagrama, Barcelona. Eta bere ingelesezko bertsioa, SACKS O. 2007. Musicophilia, Alfred A. Knopf Inc., Random House, Toronto, Canada.

[12] BERNATZKY, G., PRESCH, M., ANDERSON, M., PANKSEPP, J. 2011. «Emotional foundations of music as a non-pharmacological pain management tool in modern medicine». Neuroscience \& Biobehavioral Reviews, 35(9), 1989-1999.

[13] MEYMANDI, A. 2009. «Music, medicine, healing, and the genome project». Psychiatry (Edgmont), 6(9), 43-45.

[14] ALTMANN, J. 1999. Acoustic Weapons--a Prospective Assessment: Sources, Propagation, and Effects of Strong Sound. Cornell University Peace Studies Program, Ithaca, NY.

[15] KÄHÄRI, K., ZACHAU, G., EKLÖF, M., SANDSJÖ, L., MÖLLER, C. 2003. «Assessment of hearing and hearing disorders in rock/jazz musicians: Evaluación de la audición y de los problemas auditivos en músicos de rock y jazz». International journal of audiology, 42(5), 279-288.

[16] EMMERICH, E., RUDEL, L., RICHTER, F. 2008. «Is the audiologic status of professional musicians a reflection of the noise exposure in classical orchestral music? ». European Archives of Oto-Rhino-Laryngology, 265(7), 753-758.

[17] LEE, J., BEHAR, A., KUNOV, H., WONG, W. 2005. «Musicians' noise exposure in orchestra pit». Applied Acoustics, 66(8), 919-931.

[18] Real Decreto 286/2006, de 10 de marzo, sobre la protección de la salud y la seguridad de los trabajadores contra los riesgos relacionados con la exposición al ruido. BOE-A-2006-4414. 
[19] INSTITUTO NACIONAL DE SEGURIDAD E HIGIENE EN EL TRABAJO 2011. Ruido en los sectores de la música y el ocio: código de conducta con orientaciones prácticas para el cumplimiento del Real Decreto 286/2006 en los sectores de la música y el ocio. ISBN 978-84-7425789-2. - NIPO 792-11-020-7. 78p.

[20] Darwin, C. 1981. The descent of man, and selection in relation to sex. Princeton University Press, Princeton, New Jersey, USA. 